\title{
Investigação Temática na Formação de Professores: Indicativos da Pesquisa em Educação em Ciências ${ }^{1}$
}

\section{Thematic Investigation in Teacher Training: the Research Indicatives Regarding Science Education}

\author{
Cleilde Aguiar Neres \\ Simoni Tormohlen Gehlen \\ Brasil \\ Brasil
}

O presente estudo identifica pesquisas que utilizam os pressupostos freireanos na proposição de processos formativos de professores de Ciências e investiga como as etapas da Investigação Temática estão sendo inseridas no contexto da formação inicial e continuada de professores. Para atender aos objetivos propostos, a metodologia de trabalho estruturou-se segundo dois encaminhamentos complementares: a localização de pesquisas em Educação em Ciências que utilizam pressupostos freireanos em processos formativos de professores, a partir das Atas do Encontro Nacional de Pesquisa em Educação em Ciências (ENPEC) e de periódicos brasileiros, no período de 2010 a 2015; e entrevistas semiestruturadas com pesquisadores da área de Educação em Ciências, os quais abordam o processo de Investigação Temática no contexto da formação inicial e continuada de professores de Ciências. As entrevistas foram audiogravadas e, posteriormente, analisadas por meio da Análise Textual Discursiva. Os resultados indicam que a Investigação Temática tem sido desenvolvida com maior frequência no contexto da formação inicial de professores do que na formação continuada, sendo o Levantamento Preliminar, a Análise das Situações Significativas e a Redução Temática, as etapas mais exploradas durante os processos formativos, havendo pouca ênfase no desenvolvimento das etapas de codificação/descodificação.

Palavras-chave: Ensino de Ciências; Formação de professores; Pesquisa; Paulo Freire.

The present study identifies studies that use the Freirean assumptions in the proposal of formative processes of science teachers. It also explores how the stages of Thematic Investigation are being inserted in the context of teachers' initial and continued education. In order to meet the objectives, the methodology was structured over two complementary paths: the identification of the Science Education that uses Freirean assumptions in teacher training processes, on the Annals of the Brazilian Meeting of Research in Science Education (ENPEC) and Brazilian journals published, from 2010 to 2015, as well as on semi-structured interviews with Science Education researchers who

1 Versão inicial deste estudo foi apresentada no XI Encontro Nacional de Pesquisa em Educação em Ciências (ENPEC), Florianópolis, 2017. 
address the Thematic Investigation process in the context of both initial and continued science teachers training. The interviews were audio recorded and analyzed through the Discursive Textual Analysis method. The results indicate that Thematic Investigation has been developed more frequently in the context of initial teacher training than in the continued one, being the Preliminary Survey, the Analysis the Significant Situations, and the Thematic Reduction, the most explored stages during the formative processes, with little emphasis on the development of coding/decoding steps.

Keywords: Science Teaching; Teacher Training; Research; Paulo Freire.

\section{Introdução}

A deficiência na formação de professores e a fragmentação do currículo são apontados, por alguns estudos (Carvalho, \& Gil-Pérez, 2003; Fourez, 2003; Severino, 2003), como fatores que contribuem para a existência de uma crise no Ensino de Ciências. Neste sentido, há pesquisas que têm promovido processos de formação continuada de professores pautando-se em propostas de reorientação curricular, e que, por consequência, apresentam contribuições para minimizar alguns problemas do contexto escolar, a exemplo da falta de relação entre os conteúdos programáticos e a vivência dos alunos. Algumas dessas propostas - Abordagem Temática Freireana, dos Currículos com ênfase em Ciência, Tecnologia e Sociedade (CTS), dos Temas Conceituais e da Situação de Estudo - buscam a inserção de temas para a reestruturação e desenvolvimento do currículo (Halmenschlager, 2011).

Nesta perspectiva, destacam-se pesquisas que têm como foco a abordagem de temas pautados no referencial freireano, a exemplo dos trabalhos de Delizoicov (1982; 2008), Silva (2004), Stuani (2010; 2016), Magalhães et al. (2016), Mendonça (2016) e Centa e Muenchen (2018), dentre outros, que se baseiam na transposição das ideias de Paulo Freire para o contexto escolar. De modo geral, as pesquisas propõem a reconfiguração curricular acompanhada de reflexões acerca da formação e prática docente (Saul, 2012). Os pressupostos teórico-metodológicos da educação problematizadora e dialógica, concebidos por Paulo Freire, são empregados no ensino de Ciências, em propostas com foco na reconfiguração curricular, a exemplo da "Abordagem Temática Freireana" (ATF) (Delizoicov, Angotti, \& Pernambuco, 2011) e da "Práxis Curricular via Tema Gerador" (Silva, 2004). Nestas propostas, os conteúdos e conceitos científicos, que farão parte do processo de ensino-aprendizagem, são selecionados a partir de Temas Geradores, que emergem da realidade dos educandos e expressam contradições vividas por eles (Freire, 1987). O processo de identificação de situações-limite e a obtenção desses temas é denominado por Freire de Investigação Temática, e vem sendo implementado no Ensino de Ciências e em processos formativos de professores da área desde a década de 1980, em diversos contextos (Centa, \& Muenchen, 2018; Furlan et al., 2011; Lambach, 2013; Magalhães et al., 2016; Mendonça, 2016; Rambo, 2017; Silva, 2004; Sousa et al., 2014; Stuani, 2010; Torres et al., 2008). 
Com base em Torres (2010), entende-se que são incipientes as iniciativas que disseminam esta dinâmica em processos formativos de professores de Ensino de Ciências, visto que, muitas vezes, eles trabalham com temas que dizem ser geradores, sem realizar nenhuma das etapas da Investigação Temática, originando uma polissemia em torno do termo (Fonseca et al., 2015; Torres, 2010), e desconfigurando os fundamentos teórico-metodológicos da proposta. Nesse contexto, emerge a seguinte questão: "Como a Investigação Temática têm sido desenvolvida em processos formativos de professores de Ciências pautados na perspectiva de educação freireana?”. Para responder tal questão, busca-se identificar estudos que utilizam os pressupostos freireanos em processos formativos de professores de Ciências e investigar como pesquisadores estão desenvolvendo etapas da Investigação Temática no contexto da formação inicial e continuada de professores. A identificação destes aspectos pode contribuir para que novos processos formativos, baseados na obtenção e desenvolvimento de Temas Geradores, possam ser implementados no contexto da Educação Básica.

\section{O processo de Investigação Temática}

Freire (1967) desenvolveu, no contexto da educação não formal, uma prática de alfabetização para adultos, que consistia na utilização de Palavras Geradoras. Estas palavras, retiradas do contexto em que se encontravam os alfabetizandos, seriam uma forma de promover um ensino mais significativo, desenvolvendo a criticidade e superando a consciência ingênua sobre a realidade (Freire, 1967). Como deveriam atender à proposta dialógica e libertadora de educação, as Palavras Geradoras não poderiam ser palavras quaisquer, mas deveriam fazer referência a situações reais, além de serem ricas sócio, política e foneticamente.

E se já pensávamos em método ativo que fosse capaz de criticizar o homem através do debate de situações desafiadoras, postas diante do grupo, estas situações teriam de ser existenciais para os grupos. Fora disso, estaríamos repetindo os erros de uma educação alienada, por isso instrumental (Freire, 1967, p. 106).

Desta forma, Freire (1967) propôs algumas fases para obtenção e utilização de tais palavras, que podem ser assim sistematizadas: 1) Levantamento do universo vocabular: fase de obtenção das Palavras Geradoras, realizada a partir de conversas informais com moradores da área onde será realizado o processo educativo (Freire, 1967); 2) Seleção das palavras significativas: nesta fase são selecionadas as palavras, dentre as que foram obtidas no levantamento, que possuem maior valor sintático, semântico e maior potencial conscientizador (Freire, 1967). Nesta etapa, Freire (1967) analisa: i) Criação de situações existenciais: são realizadas codificações de situações-problemas, que contém elementos a serem debatidos e descodificados pelo grupo; ii) Elaboração de fichasroteiro: construção de fichas que servem como guias para o trabalho dos coordenadores de debate; iii) Elaboração de fichas com as Palavras Geradoras: são confeccionadas fichas contendo as Palavras Geradoras decompostas em famílias fonêmicas.

Assim como propôs fases para a obtenção e utilização das Palavras Geradoras, no 
âmbito da alfabetização de adultos (Freire, 1967), Paulo Freire também estabeleceu etapas para a apreensão de Temas Geradores, no contexto da pós alfabetização (Freire, 1987). Para ele, "se, na etapa da alfabetização, a educação problematizadora e da comunicação busca e investiga a 'palavra geradora', na pós-alfabetização, busca e investiga o 'tema gerador"” (Freire, 1987, p. 102)”. No livro "Pedagogia do Oprimido" Freire (1987) explicita que, para não haver uma "invasão cultural", o conteúdo programático da educação libertadora, no contexto da pós alfabetização, deve ser organizado por meio de Temas Geradores, os quais são temas que emergem da realidade dos sujeitos e expressam contradições vividas por eles. Investigação Temática foi o nome atribuído por Freire ao processo por meio do qual se busca as situações-limite e os Temas Geradores que as representam. Assim, “investigar o 'tema gerador' é investigar, repitamos, o pensar dos homens referido à realidade, é investigar seu atuar sobre a realidade, que é sua práxis (Freire, 1987, p. 98).

Ao aliar o Tema Gerador à práxis humana, Freire (1987) traz como orientação um fazer educacional que considere a realidade sócio histórica dos educandos e descreve o processo de Investigação Temática, que compreende as seguintes etapas: a) Levantamento preliminar - Consiste no momento em que a equipe de investigadores busca fazer um reconhecimento das condições da localidade, por meio de visitas, conversas informais com moradores, observação dos órgãos públicos, associações comunitárias e também dados estatísticos; b) Análise das situações e eleição das codificações - realiza-se a análise das informações obtidas a partir do Levantamento Preliminar, com o intuito de apreender o "conjunto de contradições" percebidas, assim como, eleger contradições que serão utilizadas na elaboração das codificações; c) Diálogos descodificadores - a equipe de investigadores retorna à comunidade para estabelecer os diálogos descodificadores nos "Círculos de Investigação Temática". Nesta etapa ocorre a discussão problematizada das contradições vividas pela comunidade, completando a tríade 'codificação - problematização descodificação', por meio da qual se obtém o Tema Gerador. d) Redução temática estudo sistemático e interdisciplinar do material obtido na etapa anterior. Para Freire (1987), à medida que se vai analisando as gravações do círculo de investigação, vão surgindo os possíveis temas e, a partir destes, se faz a delimitação temática. Em seguida, cada especialista, dentro de sua área de atuação, elabora o planejamento de ensino. A quinta etapa da Investigação Temática, caracterizada pelas atividades em sala de aula, é uma consequência das quatro anteriores e no caso da educação de adultos, proposta por Freire, é realizada nos círculos de cultura (Delizoicov, 2008).

Destaca-se que há algumas similaridades entre as etapas da Investigação Temática e a investigação das Palavras Geradoras. A primeira etapa de ambos os procedimentos, consiste num levantamento feito no local onde se dará o processo educativo, em cujo cenário, por meio de conversas informais, a equipe de investigadores apreende a realidade da comunidade. Na segunda etapa, nas duas investigações, são propostas seleções. No caso da Palavra Geradora, a seleção está relacionada à escolha das palavras, obtidas no universo vocabular pesquisado, que farão parte da alfabetização (Freire, 1967); e, no 
caso da Investigação Temática, compreende a escolha das contradições apreendidas, que serão, ainda nesta etapa, utilizadas na elaboração das codificações.

É possível considerar que o pensamento de Freire em relação às fases da investigação das Palavras Geradoras, desenvolvidas durante a alfabetização de adultos, consiste num conjunto de ideias que, posteriormente, dariam origem às etapas da Investigação Temática, sendo que esta não surgiu arbitrariamente e guarda uma relação explícita com o processo de investigação das Palavras Geradoras. Assim, pode-se afirmar que a Investigação Temática teve sua gênese na investigação da Palavra Geradora, cuja adaptação se deu para o contexto da pós-alfabetização, trazendo consigo os princípios da problematização e da dialogicidade, característicos da educação libertadora proposta por Paulo Freire.

Embora tenha sido elaborado para o contexto da educação não formal, o processo de Investigação Temática é utilizado no âmbito da educação escolar e suas etapas foram adaptadas, pela primeira vez, no projeto "Formação de professores de Ciências Naturais", desenvolvido na Guiné Bissau entre os anos de 1979 e 1981 (Delizoicov, 1982). Além deste, outros dois projetos se destacaram na transposição dos pressupostos freireanos e da Investigação Temática para o ensino de Ciências: o projeto intitulado "Ensino de Ciências a partir de Problemas da Comunidade", realizado no Rio Grande do Norte, no período de 1984 a 1987 e o projeto "Interdisciplinaridade Via Tema Gerador" ou projeto "Inter", desenvolvido no município de São Paulo/SP, entre os anos de 1989 e 1992 (Delizoicov, 2008). Posteriormente, entre os anos de 1994 e 2003, o processo de Investigação Temática foi desenvolvido em vários municípios brasileiros ${ }^{2}$, a exemplo de Porto Alegre, no estado do Rio Grande do Sul, onde foi implementado o Movimento de Reorientação Curricular, no contexto do projeto Escola Cidadã (Silva, 2004), realizado na Secretaria Municipal (POA/SMEd, 1998). Essas experiências foram fundamentais para a inserção de pressupostos de Paulo Freire na Educação Básica, bem como para fomentar discussões acerca da formação de professores (Lambach, \& Marques, 2014; Stuani, 2016; Torres, 2010).

Apesar dessas iniciativas quanto à inserção de uma perspectiva freireana de educação no Ensino de Ciências, ainda há necessidade de aprofundamentos acerca de como estruturar o conteúdo programático da Educação Básica por meio de temas, baseado nos pressupostos de Paulo Freire. Desta forma, o processo de Investigação Temática ainda tem sido foco de estudo e configura algumas ações de diversos grupos de pesquisa como, por exemplo: Grupo de Estudos e Pesquisas Educação em Ciências em Diálogo (GEPECID), vinculado à Universidade Federal de Santa Maria (UFSM); Grupo de Estudos sobre Abordagem Temática no Ensino de Ciências (GEATEC), vinculado à Universidade Estadual de Santa Cruz (UESC); Grupo de Estudos de Práticas em Movimento (GEPEM), da Universidade Federal do Rio Grande do Norte

2 Silva (2004) também destaca os seguintes municípios: Angra dos Reis, RJ (1994-2000); Porto Alegre, RS (19952000); Chapecó, SC (1998-2003); Caxias do Sul, RS (1998-2003); Gravataí, RS (1997-1999); Vitória da Conquista, BA (1998-2000); São Paulo, SP (2001-2003); Belém, PA (2000-2002); Maceió, AL (2000-2003); Dourados, MS (2001-2003). 
(UFRN) e Grupo de Pesquisa Teorias e Fundamentos da Educação (GPTeFE), vinculado à Universidade Federal de São Carlos (UFCar).

\section{Procedimentos metodológico}

A fim de atender aos objetivos propostos, a metodologia de trabalho estrutura-se segundo dois encaminhamentos complementares:

a) Localização de pesquisas em Educação em Ciências que utilizam pressupostos freireanos em processos formativos de professores, a partir das Atas do Encontro Nacional de Pesquisa em Educação em Ciências (ENPEC) e de periódicos brasileiros, no período de 2010 a 2015. A escolha desse período teve como propósito ampliar, para os periódicos do Ensino de Ciências, o levantamento realizado por Saul (2012), que mapeou o estado das pesquisas desenvolvidas no Brasil, que utilizavam o referencial freireano, por meio de dissertações e teses publicadas no Portal da Capes, entre os anos de 1987 e 2010. Segundo a autora, foram encontrados 1441 trabalhos, distribuídos entre as áreas de Ciências Humanas, Ciências Biológicas e Exatas, sendo que a subárea de Currículo se destacou com o maior número de trabalhos $(40,52 \%)$, seguida pela Formação de Professores (12,77\%).

Os periódicos selecionados para análise da presente pesquisa foram: Revista Investigações em Ensino de Ciências (IENCI); Ciência \& Educação (CIEDUC); Alexandria: Revista de Educação em Ciência e Tecnologia (Alexandria); Ensaio: Pesquisas em Educação em Ciências (Ensaio); Caderno Brasileiro de Ensino de Física (CBEF); Revista da Sociedade Brasileira de Ensino de Biologia (SBEnBio); Revista Brasileira de Ensino de Física (RBEF); Revista Brasileira de Pesquisa em Educação em Ciências (RBPEC); Química Nova na Escola (QNEs); e Química Nova. Esses periódicos são de circulação nacional e apresentaram avaliação níveis A1, A2 e B1, B2 no Qualis ${ }^{3}$ 2014, na área de avaliação "Ensino". Do mesmo modo, também se teve como objeto de análise os anais dos ENPEC, realizados nos anos de 2011, 2013 e 2015. Estes periódicos e Anais de evento foram escolhidos devido à magnitude que os mesmos apresentam no cenário nacional em relação às discussões sobre o Ensino de Ciências, caracterizando-se como importantes fontes de socialização e divulgação das pesquisas nesta área de conhecimento.

Fases desta etapa: i) a localização dos trabalhos foi realizada por meio de consulta eletrônica às versões online dos periódicos (exceto alguns volumes da Revista da Sociedade Brasileira de Ensino de Biologia - SBenBio) e dos anais do ENPEC, referentes ao período mencionado. Localizaram-se, inicialmente, os trabalhos que fazem referência a Paulo Freire, os quais foram lidos na íntegra resultando na seleção daqueles que faziam referência a cursos/processos formativos de professores de Ciências; ii) identificação dentre os trabalhos localizados, daqueles que faziam referência à Investigação Temática, buscando-se pelo termo "Investigação Temática" nos títulos, resumos, palavras-chave e corpo dos textos.

3 A seleção dos periódicos também considerou o Sistema de Avaliação e Qualificação da Coordenação de Aperfeiçoamento de Pessoal de Nível Superior (CAPES), denominado de Qualis. 
b) Entrevistas semiestruturadas com pesquisadores da área de Educação em Ciências que abordam o processo de Investigação Temática no contexto da formação inicial e continuada de professores de Ciências. Na análise dos trabalhos, constatouse que alguns não apresentavam de forma detalhada o desenvolvimento do processo de Investigação Temática, motivo pelo qual se optou pela realização de entrevistas semiestruturadas com alguns dos autores dos artigos. Sete formadores, pesquisadores em Educação em Ciências, que publicaram pelo menos um dos artigos que abordam o processo de Investigação Temática no contexto da formação inicial ou continuada de professores de Ciências foram convidados, via e-mail, a participar da entrevista. No entanto, nem todos os pesquisadores responderam ao primeiro contato. Sendo assim, realizaramse quatro entrevistas, duas pessoalmente e duas por meio do software Skype. Destaca-se que os pesquisadores são identificados pelo sistema alfanumérico (F1, F2, F3...Fn), resguardando-se a identidade dos mesmos. As questões da entrevista seguiram, sempre que possível, o protocolo explicitado na Figura 1, a seguir:

1-Com base em seu estudo que foi publicado no periódico/evento X, que aborda questões sobre o desenvolvimento de atividades de formação de professores, tendo como referência as ideias de Paulo Freire, explique melhor como foram realizadas as atividades de formação. 2-O desenvolvimento de atividades de formação de professores envolvendo as ideias de Paulo Freire é uma proposta de sua universidade ou faz parte de um projeto seu de pesquisa ou de extensão?

3-De que forma são planejadas e desenvolvidas as atividades de formação continuada de professores envolvendo um tema gerador nas universidades ou nas escolas?

4-Como é realizado o processo de Investigação Temática? Com a equipe ou em conjunto com os professores?

Figura 1. Questões para a entrevista.

Tanto os trabalhos selecionados quanto os dados obtidos por meio das entrevistas foram analisados utilizando-se a Análise Textual Discursiva (ATD) (Moraes, \& Galiazzi, 2011), que se refere a um processo de busca de novas compreensões sobre os temas em estudo, sendo organizada em uma sequência de três componentes: a unitarização; a categorização e o metatexto. Na etapa da unitarização, realizou-se a fragmentação dos trabalhos selecionados e das entrevistas devidamente transcritas, estabelecendo as unidades de sentido (Moraes, \& Galiazzi, 2011). Tal fragmentação levou em consideração os principais aspectos das descrições realizadas pelos autores dos trabalhos e dos pesquisadores entrevistados acerca das etapas da Investigação Temática (Delizoicov, 1982). Dessa forma, as unidades de sentido foram selecionadas e agrupadas de acordo com duas categorias a priori, sendo elas:

1) Etapas do processo de Investigação Temática: estabelecida a priori tendo em vista o objetivo da pesquisa de investigar como as etapas da Investigação Temática estão sendo desenvolvidas no contexto da formação de professores. Consideraram-se as etapas 
sistematizadas por Delizoicov (1982), uma vez que este foi um dos primeiros trabalhos da área de Ensino de Ciências a transpor as ideias de Paulo Freire para o contexto da educação formal. Essa categoria foi organizada em 5 (cinco) subcategorias, que são as etapas da Investigação Temática, quais sejam: i) Levantamento preliminar: verifica-se como pesquisadores obtêm informações da comunidade escolar, quanto à concepção dos sujeitos sobre a realidade em que vivem; ii) Análise das situações e escolha das codificações: identifica-se como é realizada a análise das informações do Levantamento Preliminar e de que forma são selecionadas as apostas de situações-limite; iii) Diálogos descodificadores: o foco é a análise de como é realizada a obtenção do Tema Gerador, mediante a apresentação das codificações; iv) Redução Temática: objetiva-se compreender como são realizadas as atividades relacionadas à seleção de conteúdos e conceitos científicos necessários para compreender o Tema Gerador; iv) Sala de Aula: a análise está centrada no desenvolvimento de atividades didático-pedagógicas, elaboradas a partir do Tema Gerador, no contexto de sala de aula.

2) Situação-limite: esta categoria foi organizada com o objetivo de compreender como os processos formativos de professores de Ciências, que desenvolvem a Investigação Temática, relacionam o Tema Gerador com as situações-limite, visto que, para Freire (1987) estas devem ser identificadas na busca do Tema que orientará a programação curricular.

Como encaminhamento da análise dessas duas categorias, buscou-se responder a questão de pesquisa "Como a Investigação Temática têm sido desenvolvida em processos formativos de professores de Ciências pautados na perspectiva de educação freireana?”, que orientou a seleção de unidades de sentido dos trabalhos e entrevistas, as quais foram analisadas à luz do referencial freireano e serviram de aporte para a construção de argumentos que legitimam as categorias (Moraes, \& Galiazzi, 2011). As compreensões e relações obtidas dessa análise são apresentadas no item a seguir, que compreende o processo de comunicação dos resultados ou metatexto (Moraes, \& Galiazzi, 2011).

\section{Resultados e discussão}

Os resultados da primeira fase da pesquisa, explicitados na Tabela 1, revelam um total de 5.390 artigos publicados nas revistas ${ }^{4}$ e Anais do ENPEC, no período analisado (2011-2015).

Deste total de artigos, 532 apresentam referência a alguma obra de Paulo Freire e 219 , que representam aproximadamente $4,08 \%$ do total analisado, relacionam Paulo Freire ao campo de Formação de professores de Ciências. Quando o foco se restringiu aos trabalhos que utilizam os pressupostos freireanos no contexto de processos formativos para professores de Ciências, o montante foi reduzido para 47 artigos, ou seja, $0,87 \%$ do total publicado, que se constituiu o corpus de análise. Os dados que constam na Tabela 1 também mostram que, dos periódicos consultados, o que apresenta um maior número

4 Ressalta-se que na Revista Química Nova o levantamento se restringiu à sessão de Educação e na sétima edição da SBEnBio se restringiu à área de Formação de professores de Ciências e Biologia. 
de trabalhos que se referenciam em Freire é a IENCI, com 18,49\% dos artigos publicados nos últimos seis anos e, o que apresenta o menor número de trabalhos é a RBEF, com apenas $0,69 \%$. Por outro lado, a RBPEC e a Alexandria apresentam um maior percentual de trabalhos (respectivamente 2,70\% e 3,18\%) que se baseiam em Freire ao discutir processos formativos de professores.

Tabela 1. Trabalhos que fazem referência a Paulo Freire e à formação de professores de Ciências

\begin{tabular}{|c|c|c|c|c|c|c|c|c|c|c|}
\hline $\begin{array}{l}\text { Sigla referente } \\
\text { ao Periódico/ } \\
\text { Evento }\end{array}$ & $\begin{array}{l}\text { Período } \\
\text { analisado }\end{array}$ & $\begin{array}{l}\text { Total de } \\
\text { artigos } \\
\text { publicados }\end{array}$ & $\begin{array}{c}\begin{array}{c}\text { Total } \\
\text { de }\end{array} \\
\text { artigos } \\
\text { Freire }\end{array}$ & $\begin{array}{c}\text { Percentual } \\
\text { de artigos } \\
\text { Freire } \\
(\%)\end{array}$ & $\begin{array}{c}\text { Total de } \\
\text { artigos } \\
\text { Freire/ } \\
\text { Formação } \\
\text { de } \\
\text { professores }\end{array}$ & $\begin{array}{l}\text { Percentual } \\
\text { de artigos } \\
\text { Freire/ } \\
\text { Formação de } \\
\text { professores } \\
\text { (\%) }\end{array}$ & $\begin{array}{l}\text { Total de } \\
\text { artigos } \\
\text { Freire/ } \\
\text { Processos } \\
\text { formativos } \\
\text { para } \\
\text { professores }\end{array}$ & $\begin{array}{c}\text { Percentual } \\
\text { de artigos } \\
\text { Freire/ } \\
\text { Processos } \\
\text { formativos } \\
\text { para } \\
\text { professores } \\
\text { (\%) }\end{array}$ & $\begin{array}{c}\text { Total de } \\
\text { artigos Freire/ } \\
\text { Processos } \\
\text { formativos } \\
\text { para } \\
\text { professores } \\
\text { envolvendo a } \\
\text { Investigação } \\
\text { Temática }\end{array}$ & $\begin{array}{c}\text { Percentual de } \\
\text { artigos Freire/ } \\
\text { Processos } \\
\text { formativos para } \\
\text { professores } \\
\text { envolvendo a } \\
\text { Investigação } \\
\text { Temática (\%) }\end{array}$ \\
\hline CBEF & $2010-2015$ & 199 & 11 & 5,53 & 4 & 2,01 & 0 & 0 & 0 & 0 \\
\hline CIEDU & 2010-2015 & 390 & 32 & 8,20 & 10 & 2,56 & 2 & 0,51 & 0 & 0 \\
\hline ENSAIO & $2010-2015$ & 205 & 28 & 13,65 & 11 & 5,36 & 5 & 2,43 & 1 & 0,49 \\
\hline SBEnBio & $2010-2015$ & 163 & 17 & 10,42 & 2 & 1,23 & 2 & 1,23 & 1 & 0,61 \\
\hline QNEsc & 2010-2015 & 238 & 30 & 12,60 & 10 & 4,20 & 0 & 0 & 0 & 0 \\
\hline Química Nova & $2010-2015$ & 177 & 5 & 2,82 & 4 & 2,25 & 0 & 0 & 0 & 0 \\
\hline \multirow[t]{3}{*}{ ENPEC } & 2011 & 1009 & 124 & 12,28 & 57 & 5,65 & 8 & 0,79 & 1 & 0,10 \\
\hline & 2013 & 1060 & 81 & 7,64 & 28 & 2,77 & 9 & 0,89 & 6 & 0,57 \\
\hline & 2015 & 1272 & 120 & 9,43 & 67 & 5,26 & 8 & 0,86 & 4 & 0,31 \\
\hline Total & & 5373 & 532 & 9,90 & 219 & 4,08 & 47 & 0,87 & 20 & 0,37 \\
\hline
\end{tabular}

Dos 47 trabalhos selecionados inicialmente, 20 (vinte) abordam a Investigação Temática, sendo que destes, 6 (seis) não fizeram menção à realização de suas etapas, utilizando-a apenas como referencial para discussão. Foram eles: Watanabe-Caramello, Strieder e Gehlen (2012); Lambach, Machado e Marques (2013); Watanabe-Caramello, Zanotello e Pires (2014); Giacomini e Muenchen (2015); Silva e Medeiros (2015); Mendonça et al. (2015). Os outros 14 (catorze) trabalhos relatam o desenvolvimento de algumas das etapas da Investigação Temática e/ou a adaptação das mesmas. São eles: Montalvão Neto e Torres (2014); Furlan et al. (2011); Sousa et al. (2013); Novais et al.(2015); Stuani, Fernandes e Yamazaki (2015); Roso et al. (2015); Halmenschlager, Stuani, e Souza (2011); Aires e Lambach (2010); Demartini e Silva (2013); Soares, Diniz e Carvalho (2013); Sousa et al. (2014); Marques, Halmenschlager e Wagner (2013); Gehlen et al. (2014); Pereira e Soares Neto (2013). Esses 14 (catorze) trabalhos supracitados constituíram um novo corpus da análise (Moraes, \& Galiazzi, 2011) e os resultados obtidos foram organizados nas seguintes categorias e subcategorias: 


\section{Etapas da Investigação Temática em processos formativos de professores}

Esta categoria, definida a priori, buscou organizar os resultados da análise dos trabalhos identificados e das entrevistas, tendo como base a questão de pesquisa: "Como a Investigação Temática têm sido desenvolvida em processos formativos de professores de Ciências pautados na perspectiva de educação freireana?” Para uma melhor compreensão, esta categoria foi abordada nas seguintes subcategorias, também selecionadas a priori:

\section{i) Levantamento Preliminar}

De acordo com Delizoicov (1982), oLevantamento Preliminar consisteno momento em que a equipe de investigadores busca fazer um reconhecimento das condições da localidade, por meio de visitas, conversas informais com moradores, observação dos órgãos públicos e associações comunitárias. A análise dos trabalhos selecionados indica que esta etapa da Investigação tem sido desenvolvida de diversas formas no contexto da formação inicial de professores de Ciências. Por exemplo, Furlan et al. (2011) discorrem sobre uma experiência de construção e prática curricular fundamentada na Investigação Temática via Tema Gerador e na Rede temática freireana (Silva, 2004), no contexto do Programa Institucional de Bolsas de Iniciação à Docência (PIBID). Segundo os autores, o Levantamento Preliminar foi feito por meio de "Realização de caminhada pelo bairro onde os educadores-investigadores registraram através de fotografias vários momentos cotidianos e condições básicas de vida que lhes pareciam significativos ou contraditórios" (Furlan et al., 2011, p.5).

Também, no contexto do PIBID, Marques, Halmenschlager e Wagner(2013), tendo por objetivo analisar até que ponto propostas de ensino elaboradas e implementadas por licenciandos se aproximam de uma Abordagem Temática, apresentam os resultados de uma pesquisa realizada com catorze bolsistas, em que foram utilizados como fontes de dados os Planos de Ensino elaborados por eles e um questionário ao qual responderam. Uma das duplas de bolsistas descreveu o Levantamento Preliminar realizado com os alunos da seguinte forma:

No primeiro momento foram apresentados slides com fotos (mapa, Rio Grande do Sul, foto da cidade de Caçapava, pontos turísticos da cidade) e através dessas fotos foram feitos questionamentos, que os alunos descreveram em uma folha. Após, foi pedido aos alunos que eles tirassem fotos de aspectos positivos e negativos do seu dia a dia (Marques, Halmenschlager, \& Wagner, 2013, p.4).

Uma das autoras do trabalho acrescenta, durante a entrevista, que, além dos bolsistas, as professoras supervisoras do PIBID também foram responsáveis pelo levantamento:

[...] o levantamento da realidade, eles foram para a sala de aula, aí em conjunto com as professoras supervisoras, fizeram este levantamento a partir de diferentes perspectivas, 
alguns fizeram questionários outros vídeo, outros entrevistas, né? (F2).

A fala de F2 indica a importância da participação dos professores da unidade escolar na etapa do Levantamento Preliminar, pois, sendo estes membros desta comunidade educacional, podem atuar como "auxiliares no processo de investigação", (Freire, 1987, p. 59), ajudando na obtenção de informações relevantes para esta etapa. De acordo com Delizoicov (2008):

Esta dinâmica de busca e compreensão das situações significativas em que vive a população da qual o aluno é originário fornece parâmetros para se planejar a formação continuada dos professores para que eles empreendam esta tarefa (Delizoicov, 2008, p. 43, tradução nossa).

Neste sentido, ressalta-se que a participação dos professores supervisores, no contexto do PIBID, também pode contribuir com a formação continuada destes, uma vez que, geralmente, a universidade leva para a escola, por meio do programa, propostas de atividades distintas daquelas que os professores vivenciaram durante a formação inicial (Jardilino, \& Oliveri, 2013), a exemplo da ATF.

Outra experiência relacionada ao PIBID é relatada por Demartini e Silva (2013) que, com o objetivo de identificar temáticas geradoras capazes de tornar o ensino de ciências mais significativo, desenvolvem em uma escola estadual do município de Sorocaba-SP algumas das etapas da Investigação Temática, obtendo um Tema Gerador relacionado com a gravidez na adolescência. A etapa do Levantamento Preliminar incluiu, dentre outros, a análise do Plano de Gestão da Escola e o Plano Municipal de Saúde de Sorocaba, como mostra o seguinte excerto:

Inicialmente procurou-se fazer uma caracterização da realidade escolar de modo que, com a investigação pudesse obter- se uma temática significativa, potencialmente capaz de nortear a construção de uma programação curricular via abordagem temática. Para tal, fez se uso de análise documental (Plano de Gestão da Escola e o Plano Municipal de Saúde - Sorocaba, 2006-2009), entrevistas semiestruturadas, observações de campo. (Demartini, \& Silva, 2013, p. 4).

No contexto do estágio supervisionado, destaca-se o trabalho de Montalvão Neto e Torres (2014), os quais relatam uma experiência de planejamento e execução de aulas baseadas na ATF. Os autores afirmam que a partir do desenvolvimento das etapas da Investigação Temática e análise das falas significativas da comunidade escolar chegaram a um Tema Gerador relacionado com a violência. Neste caso, o Levantamento Preliminar envolveu, além dos alunos, professores e funcionários.

Em um primeiro momento foram realizadas entrevistas com 27 alunos e 10 professores, sendo aplicados questionários distintos a cada um desses grupos, devido as suas especificidades, mas ambos possuindo questões centrais (Montalvão Neto, \& Torres, 2014, p. 126).

Ainda no âmbito da disciplina de estágio, Stuani, Fernandes e Yamazaki (2015) relatam experiências em que foram desenvolvidas algumas etapas da Investigação 
Temática na licenciatura de educadores do campo e indígenas, tendo por objetivo apresentar as potencialidades da ATF no processo de ensino e aprendizagem. De acordo com uma das autoras, ao ser questionada sobre os procedimentos adotados nesta etapa da investigação, o Levantamento Preliminar se deu mediante a organização de um roteiro, elaborado pelos próprios estudantes:

Não, elesiam em loco. Eles, claro eles fotografaram a realidade da comunidade, trouxeram a realidade da comunidade, mas conversaram com as pessoas e, principalmente, com os estudantes. Antes disso então, a gente elaborou um roteiro de como chegar, porque a gente não sabia o que ia vir, então a gente preparou o que a gente chama de pesquisa participante, então a gente preparou um roteiro, cada grupo elaborou. 'ah...vai ser com fotos pra ver o que vem?' 'Vai ser uma conversa informal?' E cada grupo elaborou seu roteiro de pesquisa, e, a partir desse roteiro que veio, então foi vindo, foi vindo e a gente selecionou aquilo que de fato era mais marcante, era mais significativo para se trabalhar (F3, grifo nosso).

Um roteiro, semelhante ao que $\mathrm{F} 3$ descreve, também foi utilizado no contexto do projeto "Interdisciplinaridade Via Tema Gerador", desenvolvido no estado de São Paulo na década de 1990. De acordo com o Caderno 2 (São Paulo, 1990), a construção de um roteiro de ação se constitui em um dos passos do "Estudo da realidade" e corresponde a um planejamento, por meio do qual se define as estratégias, os instrumentos de obtenção de dados e a forma de registrá-los. Analisando por este aspecto, o roteiro apresenta-se como um facilitador do trabalho dos pesquisadores, pois orienta a busca por informações na localidade a ser investigada. No entanto, salienta-se que, esta rota de ação, traçada antes da visita à comunidade, pode resultar numa visão "focalista" da realidade e restringir a apreensão dos problemas em sua totalidade. Nas palavras de Freire (1987):

Assim como não é possível [...] elaborar um programa a ser doado ao povo, também não o é elaborar roteiros de pesquisa do universo temático a partir de pontos prefixados pelos investigadores que se julgam a si mesmos os sujeitos exclusivos da investigação (Freire, 1987, p. 57).

O alerta apresentado por Freire (1987), refere-se à possibilidade de a prefixação de pontos e estratégias, por meio de roteiros, originar uma limitação à investigação, assim como um olhar parcial dos pesquisadores sobre os problemas. Para o autor, na investigação dos Temas Geradores, tanto os pesquisadores quanto a comunidade são sujeitos do processo, não devendo a comunidade ser objeto passivo de uma investigação, feita a partir de uma rota preestabelecida.

No caso da formação continuada, destacam-se os trabalhos de Sousa et al. (2014) e Novais et al. (2015), ambos desenvolvidos no contexto de um grupo de estudos. Sousa et al. (2014) utilizam as relações teóricas entre as etapas da ATF e a Práxis Curricular via Tema Gerador, estabelecidas por Torres (2010), para desenvolver atividades didáticopedagógicas a partir do Tema Gerador: "Consumo de Água na comunidade do Banco da Vitória". Segundo as autoras, as aproximações iniciais com a comunidade foram 
feitas por meio de levantamento de informações em blogs, jornais e estudos acadêmicos. Novais et al. (2015) realizaram o Levantamento Preliminar tanto com os alunos da escola selecionada, por meio de questionários, quanto com os moradores da comunidade, por meio do levantamento de informações para a elaboração do Plano Municipal de Saneamento Básico, do município de Iguaí, BA, que também previa a realização desta etapa.

Embora na obra "Pedagogia do Oprimido", Freire (1987) tenha descrito a etapa inicial da Investigação Temática como aquela por meio da qual os investigadores buscam a apreensão da realidade local, principalmente, por meio de visitas e conversas informais, percebe-se, a partir da análise dos trabalhos desenvolvidos durante os processos formativos, que os recursos utilizados pelos pesquisadores são bastante diversificados, compreendendo tanto fontes secundárias como o Plano de Gestão da Escola, Plano Municipal de Saúde, Plano Municipal de Saneamento Básico, blogs e estudos acadêmicos, quanto primárias, por meio de entrevistas semiestruturadas, observações de campo, questionários etc.

Outro aspecto que chama a atenção nos trabalhos, com relação à etapa do Levantamento Preliminar, é que enquanto alguns destes relatam a presença de uma equipe de investigadores composta por licenciandos, professores supervisores (PIBID) e/ou estudantes (Furlan et al., 2011; Marques, Halmenschlager, \& Wagner, 2013; Stuani, Fernandes, \& Yamazaki, 2015) ou por componentes de grupos de estudo em parceria com professores (Sousa et al., 2014), outros são realizados por um só pesquisador (Montalvão Neto \& Torres, 2014). Neste sentido, aqueles trabalhos que realizam o levantamento em conjunto com diferentes atores sociais apresentam maior consonância com a proposta inicial de Freire (1987), que prevê a realização do processo de Investigação Temática por uma equipe interdisciplinar e membros da comunidade, possibilitando o estabelecimento de relações entre distintas visões e interpretações de uma mesma realidade, permitindo alcançar uma "visão mais rica e ampla" (São Paulo, 1990).

\section{ii) Análise das situações e escolha das codificações}

De posse das informações obtidas durante o Levantamento Preliminar, os investigadores as analisam para que, dentre as mesmas, possam ser selecionadas aquelas que representam contradições vivenciadas pela comunidade, a fim de que sejam, posteriormente, codificadas (Freire, 1987). Dos 14 (catorze) trabalhos selecionados, somente 7 (sete) explicitam o desenvolvimento desta etapa. Marques, Halmenschlager e Wagner (2013), por exemplo, relatam que nem todas as duplas de bolsistas do PIBID conseguiram realizar o processo de codificação e selecionar temáticas relevantes para os alunos. Sobre o trabalho, a formadora entrevistada, ressalta:

Alguns bolsistas, eles conseguiram fazer um processo um pouco mais em sintonia com as etapas da abordagem temática mesmo, eles conseguiram voltar para a sala de aula, depois de uma análise inicial e fazer o processo de problematização e de codificação, outros não conseguiram, tanto é que a gente tenta sempre dizer que foi uma aproximação 
com a Abordagem Temática e não a Abordagem Temática mesmo que nem todos eles conseguiram (F2).

A respeito daquelas duplas que conseguiram, as autoras destacam:

Os bolsistas, de posse do material obtido, estabeleceram relações entre os aspectos apresentados pelos alunos, identificando os que eram mais significativos para o grupo. As fotos selecionadas, que podem ser entendidas como códigos dos aspectos mais relevantes, retornaram para a sala de aula e foram problematizadas (Marques, Halmenschlager, \& Wagner, 2013, p.5).

Furlan et al. (2011) também realizaram, na segunda etapa do processo de Investigação Temática, a seleção de fotos e posterior codificação das mesmas:

[...] análise das fotografias e a escolha das imagens que melhor representavam as contradições sociais locais para a preparação do material de codificação/descodificação (Freire, 1987). Foram preparadas três atividades de codificação/descodificação (Freire, 1987), cada uma delas com imagens diferentes para garantir a diversidade das falas e possibilitar várias interpretações. (Furlan et al., 2011, p.5, grifo nosso).

Os trechos destacados acima apontam a utilização daquilo que Freire (1987) denominou de "Codificação simples", por meio da qual se utiliza apenas um canal de comunicação, que pode ser o visual, o tátil ou auditivo. No caso das fotos, empregadas pelos licenciandos como material para a codificação, o canal corresponde ao visual, cuja seleção requer prudência, uma vez que sua utilização depende das situações que estão sendo codificadas e da experiência de leitura dos estudantes (Freire, 1987).

Os trabalhos de Montalvão Neto e Torres (2014) e Demartini e Silva (2013) utilizaram outras formas para analisar as contradições. Por exemplo, Montalvão Neto e Torres (2014) descrevem o uso de uma matriz 10x10, que sintetiza as variáveis levantadas no estudo da realidade, tais como moradia, transporte, trabalho, segurança, etc., possibilitando o levantamento de situações significativas, por meio do cruzamento de dados, para identificar as contradições da comunidade escolar. Enquanto Demartini e Silva (2013), o fazem a partir da análise das entrevistas. No entanto, apesar dos autores mencionarem a análise das contradições, não descrevem a elaboração das codificações. Segundo Montalvão Neto e Torres (2014):

Mesmo diante de muitos avanços nesta forma de conduzir o Ensino de Ciências na Educação Fundamental, reconhecemos alguns limites, principalmente nas etapas $2 \mathrm{e}$ 3 da ATF, a exemplo da não elaboração de codificações representativas da situaçãolimite identificada e sua posterior descodificação e legitimação em grupo- o que ficou a nosso cargo (Montalvão Neto, \& Torres, 2014, p.132, grifo nosso).

Como base neste excerto, pode-se afirmar que os próprios autores reconhecem a importância da codificação e descodificação para a legitimação do Tema Gerador e assumem que a ausência desta etapa no processo de Investigação Temática, configura-se numa adaptação da mesma.

No contexto da formação continuada, Sousa et al. (2014) descrevem a elaboração 
de um painel contendo imagens correspondentes à hipótese de situação-limite: “Água: abastecimento e consumo acrítico", que foi, posteriormente, apresentado à comunidade. Novais et al. (2015), por sua vez, relatam a análise dos questionários respondidos pelos alunos como forma de identificar possíveis situações-limite. E, posteriormente, a problematização das falas dos alunos e dos moradores foi realizada com as professoras durante o curso de formação, de onde emergiram outras situações-limite.

Em suma, a análise realizada nesta categoria sinalizou que as imagens, principalmente, as fotografias são os materiais mais utilizados pelos pesquisadores na etapa de codificação. No entanto, além das imagens, também foram utilizadas falas e respostas de questionários. Ao classificar uma codificação como simples ou composta e ao relacioná-la com o canal de comunicação, que pode ser visual, auditivo ou tátil, Freire (1987) apresenta um leque de possibilidades para a realização desta etapa da Investigação Temática, sendo que os limites se encontram no tipo de situação a ser codificada e no público que participará da descodificação.

\section{iii) Diálogos descodificadores}

Esta é a etapa em que a equipe de investigadores retorna à comunidade para estabelecer os diálogos descodificadores nos "círculos de investigação temática" (Freire, 1987). Dos trabalhos analisados sobre a formação inicial, apenas dois explicitam a realização desta etapa. Em ambos, a comunidade é a escolar e seus membros são os alunos, que juntamente com os bolsistas do PIBID realizam o processo de descodificação, conforme é possível verificar nos seguintes excertos:

A escolha do tema foi feita a partir [...] da descodificação em que foi realizada uma discussão em sala sobre as fotos [...] cada aluno pode levar cinco fotos sobre sua realidade estes puderam explicar as fotos (as quais foram escolhidas previamente pelas bolsistas), o porquê tirar aquela foto e não outra e qual a relevância para si e para os outros. (Marques, Halmenschlager, \& Wagner, 2013, p.5).

O material construído de codificações/descodificação foi analisado pelos educandos em sala de aula e a partir das significações obtidas foram selecionadas falas (Furlan et al., 2011, p.5).

$\mathrm{Na}$ formação continuada, Sousa et al. (2014) descrevem a realização dos Diálogos descodificadores em dois momentos: um com os moradores e outro com os professores.

Diálogos descodificadores - a partir dos quais foi identificada a visão da comunidade acerca da hipótese emergida junto aos professores no momento anterior. [...] Esse momento apresenta aspectos relacionados à etapa da descodificação na medida em que, ao apresentar as falas dos moradores da comunidade local sobre a hipótese problemática, os professores puderam identificar diferentes visões de mundo, além de expor seus entendimentos sobre os posicionamentos dos moradores, complementando com outras questões sociais e culturais envolvidas. (Sousa et al., 2014, p.165-166). 
Para Freire (1979), é por meio dos Diálogos descodificadores que educadores e educandos se distanciam da situação existencial apresentada, podendo "refletir juntos, de modo crítico, sobre o objeto que os mediatiza" (Freire, 1979, p.18), chegando assim, ao conhecimento crítico. É a partir das etapas de codificação/descodificação que os sujeitos são chamados a refletir e analisar as situações existenciais que os envolvem, de tal maneira que os levem ao "desvelamento da realidade". A respeito de um episódio ocorrido em Nova York em 1967, numa discussão sobre uma fotografia, em um processo de descodificação, Freire (1981) descreve a atitude de um homem:

Olhando silenciosamente a foto em seus pormenores - latas de lixo, pouca higiene, aspectos típicos de uma área discriminada - disse, de repente: 'Vivo aqui. Ando diariamente nessas ruas. Não posso dizer que jamais tivesse visto isto. Agora, porém, percebo que não percebia' (Freire, 1981, p. 18).

Possibilitar que os indivíduos observem, de forma crítica, aspectos da realidade que até então pareciam imperceptíveis, ilustra a importância da codificação/descodificação durante a Investigação Temática. No entanto, a partir dos artigos analisados, compreendese que há uma lacuna na realização destas etapas em processos formativos que ocorrem tanto no âmbito da licenciatura, como na formação continuada. A não realização das etapas de Codificação e Descodificação compromete o processo de Investigação Temática, uma vez que é por meio delas que os sujeitos envolvidos no processo educativo se distanciam das situações existenciais e são convidados a tecer um novo olhar sobre as mesmas, legitimando as contradições identificadas pelos investigadores e apontando para o Tema Gerador. Para Freire (1987), as etapas da Codificação e da Descodificação complementam o Levantamento Preliminar, que não é suficiente para localizar as situações-limite, uma vez que as contradições identificadas da realidade dos sujeitos ainda são a visão dos pesquisadores. Freire também esclarece o fato de os investigadores chegarem “ à apreensão mais ou menos aproximada do conjunto de contradições, não os autoriza a pensar na estruturação do conteúdo programático da ação educativa. Até então, esta visão é deles ainda, e não a dos indivíduos" (Freire, 1987, p.62, grifo do autor).

Corroborando com Freire (1987), ao fazer uma releitura do processo de Investigação Temática, Silva (2004) reitera a importância da realização das etapas de Codificação e Descodificação, pois, por meio delas, se dará a obtenção e análise das falas significativas, nas quais:

[...] enfatizam-se as contradições sociais vivenciadas pelos moradores, falas significativas frequentemente presentes e ricas no sentido emocional e aquelas que, embora implicitamente presentes, não têm a percepção direta dos indivíduos entrevistados. Estas são o cerne da proposta pedagógica, ou seja, devemos perceber os limites explicativos da comunidade, seus conflitos e contradições, a partir de um enfoque analítico mais contextualizado e amplo (Silva, 2004, p.205).

A complexidade de interpretações que as falas significativas da comunidade revelam, ratifica a importância das etapas de Codificação e Descodificação no processo 
de Investigação Temática, uma vez que, por meio delas, pode-se garantir a obtenção e legitimação de situações-limite, essenciais para o Tema Gerador.

\section{iv) Redução Temática}

Nesta etapa se dá o estudo sistemático e interdisciplinar do material obtido na etapa anterior e a seleção dos conteúdos específicos, que possibilitarão a compreensão do tema (Delizoicov, 1982), assim como o planejamento do ensino. No que tange ao desenvolvimento da etapa da Redução Temática, a maioria dos trabalhos analisados a descreve como um trabalho coletivo, no qual a elaboração da programação curricular é realizada por meio da articulação de conhecimentos da Química, da Física, da Biologia e, em alguns casos, da Matemática, como apontam os excertos a seguir:

O processo de seleção de conceitos e conteúdos necessários para compreensão do Tema Gerador também foi realizado nesta etapa, em que foram eleitos alguns conhecimentos científicos de Física, Química, Biologia e Matemática (Sousa et al., 2014, p.170).

Sobre esta elaboração, F3 destaca:

E, a partir daí então, a gente, junto com eles, foi organizando as programações, a programação e, da programação saíram as aulas. Então eles trabalharam Física e Matemática juntos no Ensino Médio e Química e Biologia, e Ciências e Matemática no Ensino Fundamental (F3).

A elaboração curricular envolvendo diversas disciplinas é realizada em consonância com Freire (1987) que, ao descrever o processo de Redução Temática em "Pedagogia do Oprimido", ressalta a importância da presença de especialistas de diversas áreas, responsáveis por articular seus saberes, para selecionar os conhecimentos historicamente construídos, necessários à compreensão do Tema (Freire, 1987). Apesar das experiências aqui analisadas terem sido desenvolvidas no contexto da formação de professores de Ciências, alguns autores destacaram a importância de se abordar aspectos históricos e sociais relacionados ao tema, para que houvesse maior compreensão do mesmo:

No caso do estudo da gravidez na adolescência, permite romper com as programações que privilegiam somente aspectos biológicos, como se os sujeitos compartilhassem a mesma condição biológica independentemente do contexto histórico cultural que se encontram [...]. Repressão da Sexualidade na Sociedade: inter-relações entre religião, modelo socioeconômico e contexto histórico (Demartini, \& Silva, 2013, p.7).

A inclusão de aspectos históricos e sociais foi sistematizada nos trabalhos, principalmente, por meio da Rede Temática, que consiste numa contribuição de Silva (2004) para o processo de Investigação Temática. Na Rede, encontra-se a visão da comunidade e dos educadores, que juntos contribuem para a construção da programação curricular, tendo como foco a análise dos problemas locais.

Os trabalhos de Demartini e Silva (2013), Sousa et al. (2014), Novais et al. (2015) e Furlan et al. (2011), descrevem a construção da Rede Temática durante a etapa da 
Redução Temática, conforme é possível observar nos seguintes trechos:

A partir da reflexão realizada na redução temática iniciou-se a construção da rede temática que constitui uma representação gráfica das relações entre o pensar da comunidadeeducando-educadores permite a visualização da temática em sua totalidade (Silva, 2007) (Furlan et al., 2011, p.6).

Baseados no tema gerador e no contratema, construiu-se a rede temática, visando a maior compreensão dos fatores socioculturais e políticos em nível macro, meso e microssocial que interagem se relacionando com o fenômeno da Gravidez na Adolescência (Demartini, \& Silva, 2013, p.6, grifo nosso).

Nessa fase, também realizou-se a sistematização, por parte do GEATEC/UESC, das falas da comunidade local e dos professores, em forma de uma Rede Temática, inspirada na proposta de Silva (2004) (Sousa et al., 2014, p.167).

Além de contemplar conhecimentos específicos a serem incluídos na programação curricular, que visa a superação das situações-limite representadas nas falas da comunidade, a estrutura da Rede abrange também algumas ações a serem desenvolvidas pelo poder público, tais como a coleta de lixo (Sousa et al., 2014) e políticas de habitação (Furlan et al., 2011).

No planejamento do ensino, realizado também nesta etapa, os pesquisadores geralmente utilizam os Três Momentos Pedagógicos (3MP) (Delizoicov, Angotti, \& Pernambuco, 2011) como eixos estruturadores, atrelando-os às falas significativas, propostas por Silva (2004), como apresentado nos estudos de Sousa et al. (2014) e Novais et al. (2015):

Seguindo o IV Momento, proposto por Silva (2004), foram selecionadas falas dos moradores locais a partir das quais organizou-se as unidades do planejamento, por meio da dinâmica dos Três Momentos Pedagógicos (Sousa et al., 2014, p. 170).

[...] foram elaboradas, em parceria com as professoras, as atividades didático-pedagógicas relacionadas ao tema tendo como referência as falas dos educandos e moradores. O planejamento seguiu os Momentos Pedagógicos (Novais et al., 2015, p.7).

Além dos 3MP, outros elementos utilizados na Redução Temática são os Conceitos Unificadores $^{5}$ que, de acordo com Angotti (1991):

[...] são complementares aos Temas e carregam para o processo de ensino-aprendizagem a veia epistêmica, na medida em que identificam os aspectos mais partilhados (em cada época) pelas comunidades de C\&T (Ciência \& Tecnologia), sem negligenciar os aspectos conflitivos. No campo cognitivo, tais conceitos constituem ganchos teóricos que podem articular/organizar conhecimentos aparentemente distintos em níveis intra e interdisciplinar (Angotti, 1991, p. 108, grifo do autor).

No entanto, nenhum dos trabalhos analisados menciona a adoção de Conceitos Unificadores. F2, por exemplo, tece o seguinte comentário sobre esta ausência:

\footnotetext{
5 Angotti (1991) propõe quatro conceitos unificadores: transformações, regularidades, energia e escala.
} 
[...] outra coisa que não se conseguiu fazer em nenhum dos dois contextos, principalmente agora na licenciatura, foi trabalhar com os conceitos unificadores, eu não consegui discutir com eles nem quando eu abordei a parte teórica, né, então a gente fez o processo de redução temática, mas eles sabiam que existiam, porque foi comentado, mas não foi levado em consideração pra estruturar, né, a programação a partir do tema (F2).

Como visto, a análise dos trabalhos e a fala de F2 sinalizam uma lacuna na etapa da Redução Temática, realizada em processos formativos de professores, relacionada à ausência dos Conceitos Unificadores na organização da programação curricular, que pode, consequentemente, resultar numa menor articulação entre os conhecimentos científicos, selecionados para a compreensão do Tema.

Em suma, dos 14 (catorze) trabalhos que abordam a Investigação Temática na formação inicial e continuada, 5 (cinco) descrevem a etapa da Redução Temática, que é uma fase de vital importância para a organização do currículo, uma vez que, ignorá-la, pressupõe a utilização de conhecimentos previamente estruturados, contradizendo a reconfiguração curricular a partir do Tema Gerador (Delizoicov, 2008; 1991).

\section{v) Sala de aula}

Etapa na qual se desenvolve o Tema Gerador, no contexto da educação formal, utilizando, geralmente, a dinâmica dos 3MP (Delizoicov, Angotti, \& Pernambuco, 2011). Dentre os trabalhos analisados, aqueles que apresentam a etapa da Sala de aula, mencionam sua organização por meio da dinâmica dos 3MP, como é o caso de Furlan et al. (2011), Demartini e Silva (2013) e Montalvão Neto e Torres (2014):

As práticas desenvolvidas com os alunos, durante as aulas de ciências cedidas pelo professor, foram didático-pedagogicamente organizadas de acordo com Delizoicov (2008), que propõe a divisão de três momentos para cada ação educativa: problematização inicial, aprofundamento teórico e aplicação do conhecimento (Furlan et al., 2011, p. 8).

De forma a abarcar conteúdos de Ciências, a aula foi planejada de acordo com os momentos pedagógicos, tendo por base uma questão geradora da aula (Montalvão Neto, \& Torres, 2014, p. 128, grifo do autor).

A utilização dos 3MP como organizadores do trabalho em sala de aula pressupõe a presença da dialogicidade e da problematização também nesta etapa da Investigação Temática. Seu uso, arbitrário e mecânico, a transforma numa simples metodologia que desconsidera a importância das quatro etapas anteriores desenvolvidas para a obtenção, estudo e sistematização dos Temas Geradores até chegar à etapa da Sala de aula. Por sua vez, esta etapa não foi contemplada por todos os trabalhos investigados, sendo que, em certos casos, as atividades didático-pedagógicas desenvolvidas durante a organização curricular não chegaram a ser implementadas ou o pesquisador desenvolveu somente uma aula. Demartini e Silva (2013) organizaram atividades para o nono ano do Ensino Fundamental, tendo como referência os $3 \mathrm{MP}$, em que os professores que participaram do curso de formação desenvolveram: 
[...] a partir da programação curricular proposta, uma aula segundo os três momentos pedagógicos enunciados por Delizoicov; Angotti e Pernambuco (2011) foi preparada e implementada para uma sala da $8^{\circ}$ série/ $9^{\circ}$ ano do ensino fundamental" (Demartini, \& Silva, 2013, p.7).

Muitas vezes, a dificuldade para a implementação das aulas está relacionada à resistência dos professores regentes, que ainda estão "presos" ao currículo estabelecido pela escola. As falas de F2 e F3 exemplificam tal dificuldade:

[...] a escola também trouxe algumas demandas, então a gente tentou, e no primeiro momento a escola não gostou muito da ideia, digamos assim, achou estranhos os temas [...] então, quando a gente foi com esses temas pra escola, socializar com os professores, isso gerou uma certa estranheza, eles não aceitaram no primeiro momento e eles disseram, 'não, vocês vão ter que trabalhar em cima da lista de conteúdos que nós temos' (F2, grifo nosso).

E, uma coisa, um fato que me chamou bastante atenção, que geralmente a abordagem temática quando trabalha com professores do Ensino Fundamental há muita resistência, né? Muita resistência no sentido de que 'ah... não dá conta de trabalhar 'os conteúdos mínimos, não prepara pra o vestibular' e um monte de outras questões (F3, grifo nosso).

Na formação inicial também trabalhei ela (Abordagem Temática Freireana) na Biologia, só que no curso de Biologia fica mais restrito, porque quando eles vão para a escola, aí tem que seguir aquele currículo mínimo que a escola pontua, né? Que a professora pontua, é mais complicado (F3 - grifo nosso).

Neste sentido, de acordo com as falas de F2 e F3, pode-se afirmar que a visão tradicional de educação limita a implementação de currículos críticos, que valorizem a realidade dos estudantes, como são aqueles baseados na ATF. Alves e Silva (2015) apontam que a raiz do problema se encontra no autoritarismo da cultura escolar tradicional, normalmente compartilhada pelos professores, que os impede de adotar currículos mais contextualizados e reflexivos, caracterizando uma limitação denominada de "Medo da Liberdade" (Alves, \& Silva, 2015). Em outras palavras, por mais que sejam oferecidos a estes professores oportunidades de exercer uma prática pedagógica autônoma e inovadora, muitas vezes eles não a realizam por sentirem-se mais seguros seguindo currículos pré-estabelecidos. O desenvolvimento de processos formativos, baseados nos pressupostos freireanos, com foco na formação permanente do professor (Lambach, 2013; Stuani, 2016) pode contribuir para superar esse "Medo da Liberdade", uma vez que o educador será sujeito do processo de construção curricular, passando de opositor a colaborador da elaboração de propostas didático-pedagógicas (Bonfim, 2018).

\section{Situação-limite}

Segundo Freire (1987), situações-limite são obstáculos que os sujeitos encontram em suas vidas pessoal e social, que atrapalham o exercício da liberdade e que precisam ser 
ultrapassados. Estas situações guardam uma relação intrínseca com os Temas Geradores, de tal modo que, investigar tais temas implica em investigar também as situações-limite. Para Silva (2004), os Temas Geradores são as próprias situações-limite, que se encontram nas falas da comunidade quando estas expressam circunstâncias conflituosas.

No que tange aos estudos analisados, cinco deles explicitam situações-limite que apontaram para o Tema Gerador. Montalvão Neto e Torres (2014), após investigação da realidade escolar, identificaram como principal situação-limite o problema da violência.

Portanto, o objetivo desse trabalho foi levantar os problemas mais significativos na perspectiva dos sujeitos investigados e trabalhá-los nas aulas de Ciências junto aos alunos, de forma a evidenciar as dificuldades presentes tanto na comunidade escolar, quanto nas comunidades em que os alunos vivem, sendo identificada como principal situação-limite (Freire, 1987) a questão da violência nas comunidades - apesar de serem apontados outros problemas referentes tanto aos aspectos internos como externos da unidade escolar. (Montalvão Neto, \& Torres, 2014, p.123, grifo nosso).

Por outro lado, as investigações realizadas por Furlan et al. (2011) e Novais et al. (2015) identificaram situações-limite que envolviam a problemática do lixo, estando estas em diferentes perspectivas.

A fala 'O lixo está em todo lugar.', expressa de maneira representativa a ideia que os educandos traziam a respeito da realidade vivenciada. [...]A fala representa uma contradição porque em nenhuma das fotografias havia uma quantidade significativa de lixo (Furlan et al., 2011, p.6, grifo dos autores).

[...] desenvolvimento de uma atividade didático-pedagógica em forma de história em quadrinhos, relacionadas às hipóteses de situações-limite, junto aos alunos, a partir da qual foi legitimada como situação-limite, o descarte do lixo, uma vez que a comunidade busca alternativas para o descarte do lixo. (Novais et al., 2015, p.4).

A superação das situações-limite, por meio do trabalho com os Temas Geradores, se configura no maior objetivo da educação problematizadora defendida por Paulo Freire (Freire, 1987). É por meio da análise das situações significativas de sua realidade que o sujeito pode desenvolver um posicionamento crítico, que o leve a reconhecer a totalidade das situações em que estão imersos, ao invés de perceber somente suas partes, dicotomizadas.

Neste sentido, eleger temas que não representem situações-limite, assim como não realizar o processo de codificação e descodificação mesmo que se tenha desenvolvido algumas etapas da Investigação Temática, leva a uma descaracterização da abordagem de temas com base em Freire, visto que estes temas representam o modo que o povo concebe a sua própria realidade. Sendo assim, defende-se que até mesmo as adaptações da proposta devem considerar a intrínseca relação existente entre a situação-limite e o Tema Gerador. Corrobora com tal constatação, o seguinte excerto:

Em outras palavras, o tema escolhido por algumas duplas de bolsistas não está em sintonia com a ideia de Tema Gerador presente na Abordagem Temática na perspectiva 
freireana, na qual a temática deve configurar um problema, uma situação-limite (Marques, Halmenschlager, \& Wagner, 2013, p.5).

Conforme destacam os autores, é preciso considerar as situações-limite no processo de obtenção de Temas Geradores, uma vez que, sem elas, o mesmo se distancia dos pressupostos de Paulo Freire. Aqui, também, chama-se a atenção para a legitimação das situações-limite, isto é, há necessidade de verificar se as falas da comunidade investigada são de fato compreensões dos seus sujeitos e não apenas suposições da equipe de educadores, que está realizando o processo de investigação. Isso porque a síntese organizacional dessas falas significativas concebe os Temas Geradores e essas orientam a sistematização da prática-pedagógica (Silva, 2004).

\section{Considerações Finais}

O principal objetivo da presente pesquisa consistiu em investigar como as etapas da Investigação Temática estão sendo inseridas no contexto da formação inicial e continuada de professores de Ciências. A revisão realizada nos eventos e periódicos revelou que apesar dos pressupostos freireanos serem bastante citados nos trabalhos da área de Educação em Ciências, são relativamente poucos os estudos que abordam a Investigação Temática e, menor ainda, o número dos trabalhos que relacionam a "dinâmica" com processos de formação de professores. Isso porque somente $0,37 \%$ do total dos trabalhos identificados fazem esta relação.

Por meio da análise dos trabalhos que relatam o desenvolvimento de algumas das etapas da Investigação Temática e/ou a adaptação das mesmas em cursos de formação de professores e, das entrevistas realizadas pelos pesquisadores, constatou-se que o processo de obtenção de Temas Geradores vem sendo desenvolvido com maior frequência no contexto da formação inicial de docentes do que na formação continuada, sendo que, dos catorze trabalhos identificados, oito foram realizados com ou por licenciandos. Além disso, essa análise apontou que as etapas da Investigação Temática, que os pesquisadores mais desenvolvem nos processos formativos são: o Levantamento Preliminar, a Análise das situações significativas e a Redução Temática, havendo uma lacuna no desenvolvimento da etapa de Sala de aula e, principalmente, na etapa em que se estabelecem as codificações e posteriores descodificações.

Os próprios autores reconhecem que a ausência de algumas destas etapas em seus estudos afeta a autenticidade do processo, tornando-os apenas adaptações deste, como é o caso, por exemplo, dos trabalhos de Soares, Diniz e Carvalho (2013), Demartini e Silva (2013) e Montalvão Neto e Torres (2014), em que as etapas de codificação e descodificação não foram realizadas. Chama-se a atenção para esse aspecto, uma vez que a ausência destas etapas pode contribuir para a interpretação de que a seleção de um Tema Gerador pode ser realizada sem legitimar as situações-limite de uma determinada comunidade e comprometer um dos principais objetivos do planejamento curricular pautado na perspectiva freireana, que é a compreensão e superação dessas situações. Contudo, os pesquisadores apontam para a potencialidade da Investigação Temática, 
uma vez que ela pode, no âmbito da formação inicial, favorecer o processo de pesquisa, ensino e extensão (Stuani, Fernandes, \& Yamazaki, 2015), contribuindo para a formação de professores mais críticos, por meio da vivência com novas propostas de organização curricular.

Nos cursos de formação permanente (Lambach, 2013; Stuani, 2016), isto pode contribuir para a reflexão crítica acerca da prática docente, propiciando aos professores uma nova forma de organização do ensino, tendo como ponto de partida para as aulas a problematização da realidade vivida pelos estudantes, assim como para criar espaços dentro da própria escola, para a discussão interdisciplinar de temas importantes para a comunidade, que possam contribuir com a melhoria do ensino (Lambach, 2013; Mendonça, 2016). Além disso, destaca-se a possibilidade de o professor avançar em relação à visão tradicional de educação, na qual se segue um currículo preestabelecido, uma vez que ele pode se tornar sujeito do processo de construção curricular, por meio da elaboração de atividades didático-pedagógicas (Bonfim, 2018).

Outro aspecto a destacar nos trabalhos analisados, refere-se à diversidade de elementos que são utilizados durante a realização da Investigação Temática e que não pertencem à proposta inicial descrita por Freire, mas às releituras que o trabalho desse autor foi sofrendo ao longo do tempo, por meio da sua transposição para o contexto do Ensino de Ciências. Por exemplo, Furlan et al. (2011); Demartini e Silva (2013), Novais et al. (2015) e Sousa et al. (2014) fazem uso das falas significativas e da Rede Temática, que são elementos propostos por Silva (2004) em sua releitura da Investigação Temática. Isso é importante, uma vez que contribui para incorporação de novos elementos à dinâmica, favorecendo sua disseminação para o contexto da Educação em Ciências. Nesse sentido, pesquisas têm sinalizado para relações entre a Investigação Temática e aspectos teóricometodológicos de Milton Santos (Fonseca, 2017), da Teoria da Atividade, proposta por Leontiev (Silva, 2015), com alguns aspectos de Vygotsky (Gehlen, 2009), e com elementos da educação Ciência-Tecnologia-Sociedade (CTS) (Almeida, 2018; Centa, \& Muenchen, 2016; Roso, \& Auler, 2016).

Por fim, ressalta-se a importância da continuidade do presente estudo em trabalhos futuros, uma vez que ainda há necessidade de se investigar de que forma o processo de Investigação Temática tem influenciado a prática pedagógica dos professores que vivenciam o seu desenvolvimento, por meio da formação inicial ou continuada. Isso se justifica porque defende-se que o desenvolvimento das etapas da Investigação Temática em processos formativos de professores de Ciências, tanto na formação inicial como na formação continuada, proporciona condições para a constituição de educadores mais críticos, capazes de contribuir, por meio do trabalho com Temas Geradores, com a emancipação dos educandos, instigando-os a questionar a realidade em que vivem, desvelando-a, refletindo e agindo sobre ela. 


\section{Agradecimentos}

Ao CNPq (Processo 471383/2014-7) pelo auxílio financeiro.

\section{Referências}

Aires, J. A., \& Lambach, M. (2010). Contextualização do Ensino de Química pela Problematização e Alfabetização Científica e Tecnológica: uma possibilidade para a formação continuada de professores. Revista Brasileira de Pesquisa em Educação em Ciências, 10(1), 1-15.

Almeida, E. S. (2018). A Investigação Temática na perspectiva da articulação Freire-CTS. (Dissertação de Mestrado em Educação em Ciências). Universidade Estadual de Santa Cruz, Ilhéus, BA.

Alves, A. H. B., \& Silva, A. F. G. (2015). Manifestações de obstáculos gnosiológicos para a seleção de conteúdos na implementação de um currículo crítico em Ciências Naturais. Alexandria - Revista de Educação em Ciência e Tecnologia, 8(1), 181-207. https://doi. org/10.5007/1982-5153.2015v8n1p181

Angotti, J. A. P. (1991). Fragmentos e totalidades no conhecimento científico e no ensino de ciências. (Tese de Doutorado em Educação). Universidade de São Paulo, São Paulo.

Bonfim, M. G. (2018). O Potencial Gnosiológico da Abordagem Temática: um olhar sobre o processo formativo de professores da EJA. (Dissertação de Mestrado em Educação em Ciências). Universidade Estadual de Santa Cruz, Ilhéus, BA.

Carvalho, A. M. P., \& Gil-Pérez, D. (2003). Formação de Professores de Ciências. 7. ed. São Paulo: Cortez.

Centa, F. G., \& Muenchen, C. (2016). O despertar de uma cultura de participação no trabalho com um Tema Gerador. Alexandria - Revista de Educação em Ciências e Tecnologia, 9(1), 263-291. https://doi.org/10.5007/1982-5153.2016v9n1p263

Centa, F. G., \& Muenchen, C. (2018). O trabalho coletivo e interdisciplinar em uma reorientação curricular na perspectiva da Abordagem Temática Freireana. Revista Eletrónica de Enseñanza de las Ciencias. 17(1), 68-93.

Delizoicov, D. (1982). Concepção problematizadora para o ensino de ciências na educação formal: relato e análise de uma prática educacional na Guiné-Bissau. (Dissertação de Mestrado em Ensino de Ciências). Instituto de Física, Universidade de São Paulo, São Paulo.

Delizoicov. D. (1991). Conhecimento, tensões e transições. (Tese de Doutorado em Educação). Universidade de São Paulo, São Paulo. 
Delizoicov, D. (2008). La Educación en Ciencias y la Perspectiva de Paulo Freire. Alexandria - Revista de Educação em Ciência e Tecnologia,1(2), 37-62. https://doi. org/10.5007/\%25x

Delizoicov, D., Angotti, J. A. P., \& Pernambuco, M. M. C. A. (2011). Ensino de Ciências: Fundamentos e Métodos. São Paulo: Cortez.

Demartini, G. R., \& Silva, A. G. (2013). Abordagem Temática na Sistematização Curricular para o Ensino de Ciências: gravidez na adolescência em uma escola estadual do município de Sorocaba-SP. In Atas do IX Encontro Nacional de Pesquisa em Educação em Ciências. Águas de Lindóia, SP.

Freire, P. (1967). Educação como pratica da liberdade. Rio de Janeiro: Paz e Terra.

Freire, P. (1979). Conscientização. São Paulo: Cortez e Moraes.

Freire, P. (1981). Ação Cultural para a Liberdade. Rio de Janeiro: Paz e Terra.

Freire, P. (1987). Pedagogia do Oprimido. 17. ed. Rio de Janeiro: Paz e Terra.

Fonseca, K. N., Novais. E. S. P., Neres, C. A., Barbosa, L. S., Milli, J. C. L., \& Gehlen, S.T. (2015). Tema Gerador em Pesquisas em Educação em Ciências. In X Encontro Nacional de Pesquisa em Educação em Ciências, Águas de Lindóia, SP.

Fonseca, K. N. (2017). Investigação Temática e a Formação Social do Espaço: construção de uma proposta com professores dos anos iniciais. (Dissertação de Mestrado em Educação em Ciências). Universidade Estadual de Santa Cruz, Ilhéus, BA.

Fourez.G. (2003). Crise no Ensino de Ciências? Revista Investigações em Ensino de Ciências Investigações em Ensino de Ciências, 8(2), 109-123.

Furlan, A. B. S., Ricci, E. C., Gomes, C. G. C., \& Silva, A. F. G. (2011). Abordagem Temática no currículo de Ciências: a perspectiva ético-crítica na concepção de lixo como condição humana. In Atas do VIII Encontro Nacional de Pesquisa em Educação em Ciências, Campinas, SP.

Gehlen, S. T. (2009). A função do problema no processo ensino-aprendizagem de ciências: contribuições de Freire e Vygotsky. (Tese de Doutorado em Educação Científica e Tecnológica). Universidade Federal de Santa Catarina, Florianópolis, SC.

Gehlen, S.T., Strieder, R. B., Watanabe-Caramello, G., Feistel, R. A. B., \& Halmenschlager. K.R. (2014). A Inserção da Abordagem Temática em cursos de Licenciatura em Física em Instituições de Ensino Superior. Revista Investigações em Ensino de Ciências, 19(1), 217-238.

Giacomini, A., \& Muenchen, C. (2015). Os Três Momentos Pedagógicos como organizadores de um processo formativo: algumas reflexões. Revista Brasileira de Pesquisa em Educação em Ciências, 15(2), 339-355. 
Halmenschlager, K. R. (2011). Abordagem temática no ensino de ciências: algumas possibilidades. Vivências: Revista Eletrônica de Extensão da URI, 7(13), 10-21.

Halmenschlager, K. R., Stuani, G. M., \& Souza, C. A. (2011). Formação docente no contexto escolar: contribuições da reconstrução curricular via Abordagem Temática. Alexandria - Revista de Educação em Ciências e Tecnologia, 4(2), 83-107. https://doi. $\operatorname{org} / 10.5007 / \% 25 \mathrm{x}$

Jardilino, J. R. L., \& Oliveri, A.M.R. (2013). A formação continuada de professores no âmbito do PIBID na região dos Inconfidentes (MG). EntreVer, 3(4), 237-249.

Lambach, M. (2013). Formação Permanente de Professores de Química da EJA na Perspectiva Dialógico-Problematizadora Freireana. (Tese de Doutorado em Educação Científica e Tecnológica). Universidade Federal de Santa Catarina, Florianópolis.

Lambach, M., \& Marques, C. A. (2014). Estilos de pensamento de professores de Química da Educação de Jovens e Adultos (EJA) do Paraná em processo de Formação Permanente. Ensaio Pesquisa em Educação em Ciências, 16(1), 85-100.

Lambach, M., Machado, A. R., \& Marques, C. A. (2013). Formação Permanente de Professores de Ciências do Ensino Médio: mudanças na prática pedagógica pela problematização crítica. In Atas do IX Encontro de Pesquisa em Educação em Ciências. Águas de Lindóia, SP.

Magalhães, R. S., Solino, A. P., Sousa, P. S., Fonseca, K. N., Novais, E. S., \& Gehlen, S. T. (2016). Situações-Limite na formação de professores de ciências na perspectiva. Investigação em Ensino de Ciências. 21(3), 127-151.

Marques, S. G., Halmenschlager, K. R., \& Wagner, C. (2013). Abordagem Temática na Iniciação à Docência. In Atas do IX Encontro de Pesquisa em Educação em Ciências. Águas de Lindóia, SP

Mendonça, A. R. (2016). A aposta da reorientação curricular via Tema Gerador no Projeto Parnamirim Interdisciplinar. (Dissertação de Mestrado em Educação). Universidade Federal do Rio Grande do Norte, Natal, RN.

Mendonça, T., Carnio, M. P., Lenharo, A. F. L., Dias, J.A., Dias, J. B., Rinaldo, R. C., Barros, W. G., \& Lopes, N. C. (2015). A construção intersubjetiva e comunicativa de uma questão sociocientífica por um grupo de professores em um pequeno grupo de pesquisa. In Atas do X Encontro Nacional de Pesquisa em Educação em Ciências. Águas de Lindóia, SP.

Montalvão Neto, A. L., \& Torres, J. R. (2014). Perspectiva de Ensino Crítico em Ciências: uma experiência docente a partir da Abordagem Temática Freireana. Revista de Ensino de Biologia da Associação Brasileira de Ensino de Biologia (SBEnBio). 7, 122-134.

Moraes, R., \& Galiazzi, M. C. (2011). Análise Textual Discursiva. 2. ed. Ijuí: Unijuí. 
Novais, E. P. S., Fonseca, K. N., Sousa, P., Magalhães, R., Solino, A. P., \& Gehlen, S. T. (2015). O processo de Redução Temática do Tema Gerador "Para onde vai o lixo do meio rural de Iguaí/BA?”. In Atas do IX Encontro Nacional de Pesquisa em Educação em Ciências. Águas de Lindóia, SP.

Pereira, P. B., \& Soares Neto, F. F. (2013). Condições de Produção de uma Aula de Energia: a formação científica de professores em Timor-Leste. In: Atas do IX Encontro Nacional de Pesquisa em Educação em Ciências. Águas de Lindóia, SP.

Porto Alegre. Secretaria Municipal de Educação. (1998). Planejando as totalidades de conhecimento na perspectiva do Tema Gerador. Cadernos Pedagógicos, $n^{\circ} 13$. Porto Alegre.

Rambo, E. M. (2017). Paulo Freire: Diálogos no âmbito da Educação Infantil - Estudo de caso do município de Concórdia - SC, 2000-2016. (Dissertação de Mestrado em Educação). Universidade Federal da Fronteira Sul, Campus Chapecó, Chapecó, SC.

Roso, C. C. \& Auler, D. (2016). A Participação na Construção do Currículo: Práticas Educativas Vinculadas ao Movimento CTS. Ciências \& Educação, 22(2), 371-389. http:// dx.doi.org/10.1590/1516-731320160020007

Roso, C. C., Santos, R., Rosa, S. E., \& Auler. D.(2015). Currículo Temático Fundamentado em Freire-CTS: engajamento de professores de Física em formação inicial. Ensaio Pesquisa em Educação em Ciências, 17(2), 372-389. http://dx.doi.org/10.1590/198321172015170205

Saul, A. M. (2012). O pensamento de Paulo Freire na educação brasileira: análise de sistemas de ensino a partir de 1990. Currículo sem Fronteiras, 12(3), 37-56.

São Paulo. Secretaria Municipal de Educação (1990). Estudo preliminar da realidade local: resgatando o cotidiano. Cadernos de Formação. São Paulo: DOT/SME-SP.

Severino, A. J. (2003). O conhecimento pedagógico e a interdisciplinaridade: o saber como intencionalização da prática. In I. C. A. Fazenda (Org.), Didática e interdisciplinaridade. (pp. 31-44). Campinas, SP: Papirus.

Silva, A. F. G. (2004). A construção do currículo na perspectiva popular crítica: das falas significativas às práticas contextualizadas. (Tese de Doutorado em Educação e Currículo). Pontifíca Universidade Católica de São Paulo, São Paulo.

Silva, A. A., \& Medeiros, D. M. (2015). Intervenção e pesquisa na formação inicial de professores de Ciências da Natureza para a Educação do Campo. In Atas do X Encontro Nacional de Pesquisa em Educação em Ciências. Águas de Lindóia, SP.

Silva, R.M. (2015). Abordagem Temática Freireana na formação de professores de ciências sob a ótica da Teoria da Atividade. (Dissertação de Mestrado em Educação Científica e Formação de Professores). Universidade Estadual do Sudoeste da Bahia, Jequié, BA. 
Soares, M. N., Diniz, R. E. S., \& Carvalho, W. L. P. (2013). A busca pela experiência formativa no estágio curricular de uma licenciatura em ciências biológicas: análise de uma proposta In Atas do IX Encontro Nacional de Pesquisa em Educação em Ciências. Águas de Lindóia, SP.

Sousa, P. S., Solino, A. P. S., Figueiredo, P. S., \& Gehlen, S. T. (2013). Abordagem Temática Freireana e a Práxis Curricular via Tema Gerador no contexto de um grupo de professores de Ciências. In Atas do IX Encontro Nacional de Pesquisa em Educação em Ciências. Águas de Lindóia, SP.

Sousa, P. S., Bastos, A. P. S., Figueiredo, P. S., \& Gehlen, S. T. (2014). Investigação Temática no Contexto do Ensino de Ciências: Relações entre a Abordagem Temática Freireana e a Práxis Curricular via Tema Gerador. Alexandria - Revista de Educação em Ciência e Tecnologia, 7(2), 155-177. https://doi.org/10.5007/\%25x

Stuani, G. M. (2010). A Construção curricular popular crítica no ensino de Ciências Naturais e suas implicações na prática docente. (Dissertação de Mestrado em Educação Científica e Tecnológica). Universidade Federal de Santa Catarina, Florianópolis, SC.

Stuani, G. M. (2016). Abordagem Temática Freireana: Uma Concepção de Formação Permanente dos Professores de Ciências. (Tese de Doutorado em Educação Científica e Tecnológica). Universidade Federal de Santa Catarina, Florianópolis, SC.

Stuani. G. M., Fernandes. C. S., \& Yamazaki. R. M. (2015). As Potencialidades da Abordagem Temática na Formação de Educadores do Campo e Indígenas. In Atas do X Encontro Nacional de Pesquisa em Educação em Ciências. Águas de Lindóia, SP.

Torres, J. R., Gehlen, S. T., Muenchen, C., Gonçalves, F. P, Lindemann, R. H., \& Gonçalves, F. J. F.(2008). Ressignificação curricular: contribuições da Investigação Temática e da Análise Textual Discursiva. Revista Brasileira de Pesquisa em Educação em Ciências, 8 (2), 1-13.

Torres, J. R. (2010). Educação Ambiental Crítico-Transformadora e Abordagem Temática Freireana. (Tese de Doorado em Educação Científica e Tecnológica). Universidade Federal de Santa Catarina, Florianópolis, SC.

Watanabe-Caramello, G., Strieder, R. B., \& Gehlen, S. T. (2012). Desafios e possibilidades para a Abordagem de Temas Ambientas em aulas de Física. Revista Brasileira de Pesquisa em Educação em Ciências, 12(1), 205-222.

Watanabe-Caramello, C. G., Zanotello, M., \& Pires, M. O. D. C. (2014). A Perspectiva Freireana na Formação Continuada de Professores de Física. Alexandria - Revista de Educação em Ciência e Tecnologia, 7(2), 51-72. https://doi.org/10.5007/\%25x 


\section{Cleilde Aguiar Neres}

(ํ) https://orcid.org/0000-0003-2288-7100 Universidade Estadual de Santa Cruz Programa de Pós-Graduação em Educação em Ciências Ilhéus, Bahia, Brasil cleu.aguiar@hotmail.com

\section{Simoni Tormohlen Gehlen}

${ }^{\circ}$ https://orcid.org/0000-0002-9786-3392

Universidade Estadual de Santa Cruz Departamento de Ciências Exatas e Tecnológicas Programa de Pós-Graduação em Educação em Ciências Ilhéus, Bahia, Brasil stgehlen@gmail.com.br

Submetido em 10 de Outubro de 2017

Aceito em 26 de Janeiro de 2018 Publicado em 29 de Abril de 2018 